\title{
El arte y la literatura en la construcción y disputa de la memoria en Guatemala ${ }^{1}$
}

\section{Arts and Literature in the Dispute and Construction of Memory in Guatemala}

\section{Arte e literatura na disputa e construção da memória na Guatemala}

Rafael Cuevas Molina

Académico investigador

Instituto de Estudios Latinoamericanos

Universidad Nacional de Costa Rica

Recibido: 10/5/2016 Aceptado: 2/6/2016

DOI: http://dx.doi.org/10.15359/tdn a.32-60.3

\section{Resumen}

La disputa entre si hubo o no genocidio en Guatemala es un generador que se mueve una parte del arte y la literatura guatemaltecos. La memoria se ha convertido en un lugar de disputa. El arte se convirtió en un espacio de expresión de aquellos que consideran que sus derechos han sido conculcados. ¿Cuáles han sido los temas que ha privilegiado el arte que tiene como eje la memoria en Guatemala? Este ensayo propone principalmente dos: la violencia y

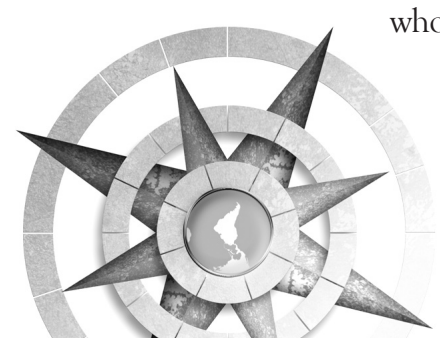

los desaparecidos. La artista performática Regina Galindo, la grabadora y dibujante Isabel Ruíz y el fotógrafo Daniel Hernández se presentan como ejemplos representativos, aunque no como los únicos artistas, en cuya obra se refleja esta temática.

Palabras clave: arte y literatura de la memoria, Regina Galindo, Isabel Ruíz, Daniel Hernández, holocausto, Guatemala, América Latina

\section{Abstract}

The dispute whether there was genocide in Guatemala is a generator that moves a part of the art and literature in this country. Memory has become a place of dispute. The art became a means of expression of those who believe their rights have been violated. What were the

El ensayo se deriva de la ponencia presentada al Simposio Artes y políticas de la memoria en Centroamérica: recordar el pasado para imaginar otro futuro, que se llevó a cabo en el Encuentro Centroamérica-Cuenta entre el 23 y 28 de abril de 2016 en Managua, Nicaragua. 
issues privileged by that art whose key is the memory in Guatemala? This paper proposes mainly two issues: violence and dissapeared ones. The performance artist Regina Galindo, the writer and artist Isabel Ruiz and photographer Daniel Hernández are presented as representative examples whose work reflected this subject.

Keywords: art and literature of memory, Regina Galindo, Isabel Ruíz, Daniel Hernández, holocaust, Guatemala, América Latina

\section{Resumo}

A disputa sobre se houve genocídio na Guatemala é um gerador que move uma parte da arte e da literatura da Guatemala. Memória tornou-se um lugar de disputa e arte tornou-se um meio de expressão daqueles que acreditam que seus direitos foram violados. Quais foram os problemas que privilegia a arte da Guatemala cuja chave e a memória? Este trabalho propõe essencialmente dois: a violência e os desaparecidos. A artista de performance, Regina Galindo, a escritora e artista Isabel Ruiz e fotógrafo Daniel Hernandez são apresentados como exemplos representativos, mas não como os únicos artistas cujo trabalho refletiu esta temática.

Palavras chave: arte e literatura da memoria, Regina Galindo, Isabel Ruíz, Daniel Hernández, holocausto, Guatemala, America-latina

Debo, en primera instancia, hacer mención de algunas limitaciones que tengo para abordar el tema de la memoria. La primera tiene que ver con aquello que Pierre Nora (1998) llama «el fin de la memoria real» a partir de la aceleración del tiempo en las sociedades modernas, que en nuestros días alcanza niveles paroxísticos que se expresan en un presentismo que tiñe toda la vida social. Me refiero a esa característica de la vida contemporánea que se desentiende y a veces le molesta el pasado, como si fuera una carga que no deja vivir.

La segunda es personal, y tiene que ver con el hecho que, al hablar de la memoria en Guatemala, hablaré sobre un tema que me toca familiarmente y, por lo tanto, en el que me cuesta ser objetivo. No intentaré la "objetividad" sino hablar desde la parcialidad; una parcialidad que a veces es análisis, a veces es descripción y a veces es denuncia, todo mezclado emotivamente. Se trata de una rememoración de hechos y acontecimientos de un tiempo en los que he estado involucrado y que interpreto de una forma que está en contradicción con las versiones que tienen otros de esos mismos hechos y acontecimientos.

Esas son, pues algunas de las limitaciones de mi postura.

En toda sociedad, y la guatemalteca no es una excepción, existen varias capas de memoria. En Guatemala, por ejemplo, existe una disputa entre la memoria de ciertos grupos étnicos respecto a

$58 \mathrm{El}$ arte y la literatura en la construcción y disputa de la memoria en Guatemala Rafael Cuevas Molina

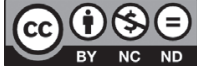

Licencia Creative Commons Atribución-No-Comercial SinDerivadas 3.0 Costa Rica.

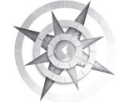


su pasado y la historia oficial o, como la llama Halbwachs (1992) la memoria oficial. No me referiré ahora a esta disputa. Me referiré a otra capa de la memoria en donde también hay disputa, pero que es más reciente: la memoria, o las memorias, del período de la guerra entre los años 1960 y 1996.

En mi opinión, el principal nudo de disputa de la memoria en la actualidad guatemalteca gira en torno al genocidio. La controversia se establece hoy, principalmente después del juicio al exgeneral Efraín Ríos Montt sobre si hubo o no genocidio.

Esta disputa toca aspectos esenciales de lo que podríamos llamar "la guatemaltequidad”, es decir, qué hemos sido y qué somos los guatemaltecos. Veamos un ejemplo: aunque en el país la guerra tocó a toda la población, los hechos que pueden ser calificados como genocidas se perpetraron fundamentalmente en el área rural, que es donde vive la mayoría de la población indígena.

En el juicio seguido al general Efraín Ríos Montt, hace un año, testificó como experta la socióloga Marta $\mathrm{Ca}$ saús Arzú. En su participación expuso la dimensión racial de la guerra. En su opinión las barbaridades cometidas tuvieron una dimensión superlativa, es decir, fueron más atroces, hubo más ensañamiento, porque los que eran reprimidos eran indígenas y no ladinos, lo cual mostró una faz característica de la guatemaltequidad dominante: el racismo, y esa identidad nacional ladina no acepta que es racista.

Otro aspecto esencial de la guatemaltequidad que toca la controversia sobre el genocidio es relativo al Ejército. En nuestra opinión, en el siglo XIX el Ejército como institución se encontró en el centro del proceso de construcción de la identidad nacional ladina dominante. No entraré en detalles al respecto. Lo que interesa resaltar ahora es que, en el marco de los juicios que hoy se llevan a cabo por asesinatos masivos, lesa humanidad y genocidio, miembros del Ejército se encuentran en el banquillo de los acusados, lo cual pone en entredicho a la institución.

Estos dos aspectos mencionados forman parte, en nuestra opinión, de esto que hemos llamado la identidad nacional ladina hegemónica que, como identidad colectiva, ha sido construida y sirve para dar cohesión y unidad a la nación guatemalteca la cual, ante estas denuncias, se muestra como incompleta, parcial y falente a tal punto que, como se evidenció en el genocidio, se estructura sobre la segregación, la discriminación y la represión; así, es propensa a la desestabilización y la ruptura.

Esta identidad ladina hegemónica considera que la muestra de sus falencias y limitaciones es una 
traición a la Patria, una ofensa a la nación, un intentó de desestabilización del orden, una venganza por la derrota en la guerra y, al ser la denuncia del genocidio lo que las evidencia, lo niega.

En nuestra opinión, este nudo formado por la disputa entre si hubo o no genocidio es el generador de lo que Antonio Brailovsky (1997) llama el ambiente cultural en el que se mueve una parte del arte y la literatura guatemaltecos, aunque no necesariamente haciendo referencia directa a él, sino expresando lo que podríamos llamar temas subsidiarios que, en este caso, guardan vínculos con el nudo generador al tratar asuntos como el de la violencia política, el miedo, la guerra, la clandestinidad o la persecución: temas oscuros propios de una nación enfrentada y desgarrada.

Otra característica que creemos que alimenta el hecho que la literatura y el arte trate estas temáticas es que en Guatemala, solo muy recientemente el aparato judicial ha podido dar pasos positivos en dirección del juzgamiento de hechos del tiempo de la guerra como los mencionados. Antes el miedo, la corrupción y la ineficiencia no daban esperanzas de que el poder judicial pudiera asumir el papel que le correspondía. Tal vez por eso el arte se convirtió en un espacio de expresión de aquellos que consideran que sus derechos han sido conculcados.

Un hecho sintomático en esta dirección es que prácticamente no existe arte que justifique o enaltezca lo hecho por las llamadas fuerzas contrainsurgentes, pues estos tienen asegurado un espacio de legitimación en la memoria oficial, transformada en historia oficial, que se transmite a través de la institucionalidad establecida y en el sentido común dominante.

¿Cuáles han sido los temas que ha privilegiado el arte que tiene como eje la memoria? En nuestra opinión, principalmente dos: la violencia y los desaparecidos. Son los casos de la artista performática Regina Galindo, de la grabadora y dibujante Isabel Ruíz y del fotógrafo Daniel Hernández que aquí trataremos como ejemplos representativos y no como los únicos artistas en cuya obra se refleja esta temática.

Regina Galindo se ha caracterizado por sus performances impactantes que tienen como referencia la violencia de la guerra y la actual contra las mujeres. Uno de sus más impresionanantes performance lo realizó en el 2003 y se llamó ¿Quién puede olvidar las huellas?. Transcribimos a continuación el texto del pintor Moisés Barrios que recoge la Página de literatura guatemalteca referente a este performance:

$60 \mathrm{El}$ arte y la literatura en la construcción y disputa de la memoria en Guatemala Rafael Cuevas Molina 
El martes 23 de julio la artista Regina José Galindo realizó un performance en la ciudad de Guatemala. Desde la fachada de la Corte de Constitucionalidad hacia el Palacio Nacional recorrió las calles del Centro Histórico con un balde lleno de sangre humana. A cada paso Galindo remojaba sus pies para luego dejar huellas sobre el pavimento. El permanente acto de silencio y cada pisada eran una forma de emular el sufrimiento de todas aquellas víctimas que murieron en el conflicto armado, un gesto simbólico ante el olvido y crítica ante la descarada pretensión del actual presidente del Congreso, Efraín Ríos Montt -el más grande genocida de la historia de este país-, de ser inscrito como candidato presidencial y optar a las elecciones presidenciales de noviembre (http://www.literaturaguatemalteca.org/rjgalindo.htm).

Los performances de Regina José Galindo, que reciben críticas casi unánimemente laudatorias fuera de Guatemala, son objeto de burla por parte del sentido común dominante guatemalteco, como lo evidencian los comentarios que se hacen a las reseñas que sobre sus trabajos aparecen en periódicos guatemaltecos, en donde se le tilda de vieja loca, "desequilibrada deseosa de llamar la atención", "vieja sin oficio" y otros epítetos similares.
Fotografía 1. Regina Galindo; ¿Quién puede borrar las huellas? Guatemala, 2003

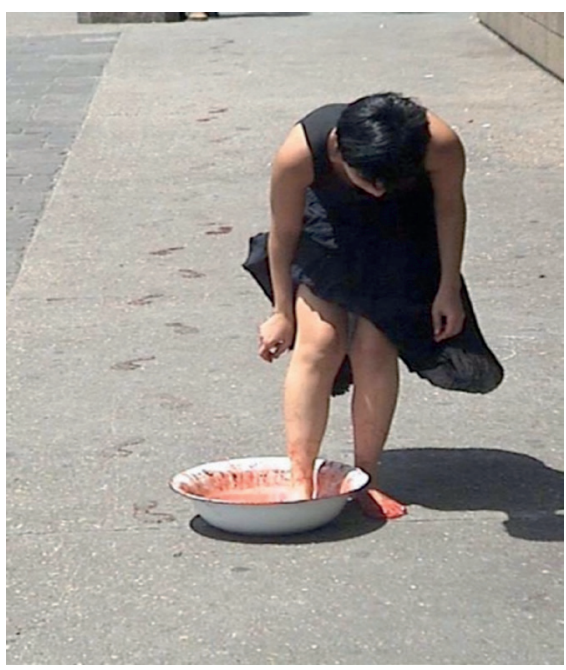

Tomado de: http://postwarelsalvador.blogspot.com/2014/07/quien-puede-borrar-lashuellas.html

De Isabel Ruíz mencionaremos aquí dos de sus trabajos: el performance realizado en Antigua Guatemala bajo el auspicio de la Cooperación española, y la serie de acuarelas e instalación conmemorativas de la masacre de Río Negro. En el primero, Ruíz hace rayas en la pared exterior del antiguo convento de la Compañía de Jesús en Antigua Guatemala. Cada raya, un desaparecido. En entrevista que le hace Anabella Acevedo, Isabel Ruíz dice:

En el marco del Día Nacional Contra las Desapariciones Forzadas, 
varios artistas guatemaltecos participamos en la primera muestra de performance organizada por el Centro de Formación de la Cooperación Española en La Antigua Guatemala, paralela a una exposición de obras latinoamericanas bajo el tema de los desaparecidos. Allí mi obra consistió en hacer cuentas con yeso sobre los muros exteriores del edificio, tal como le enseñaban a uno en la escuela: cuatro rayitas verticales y una atravesada en diagonal. Solo que lo mío tenía un propósito concreto: simbolizar el recuento de los muertos en el conflicto armado. Cuando estaba en plena performance tuve dos experiencias: un hombre pasó y dijo que me iba a meter un par de tiros por estar "destruyendo" el patrimonio, y luego, elementos de la policía municipal pretendieron llevarme, cosa que no lograron porque se había pedido permiso y además había un trabajador de la Cooperación que borraba lo que yo hacía, tal como se había convenido (http://bibliotecadigital. aecid.es/bibliodig/es/catalogo_imagenes/grupo.cmd?path=1008231).

Fotografía 2. Isabel Ruíz. Performance. Antigua Guatemala, 2008

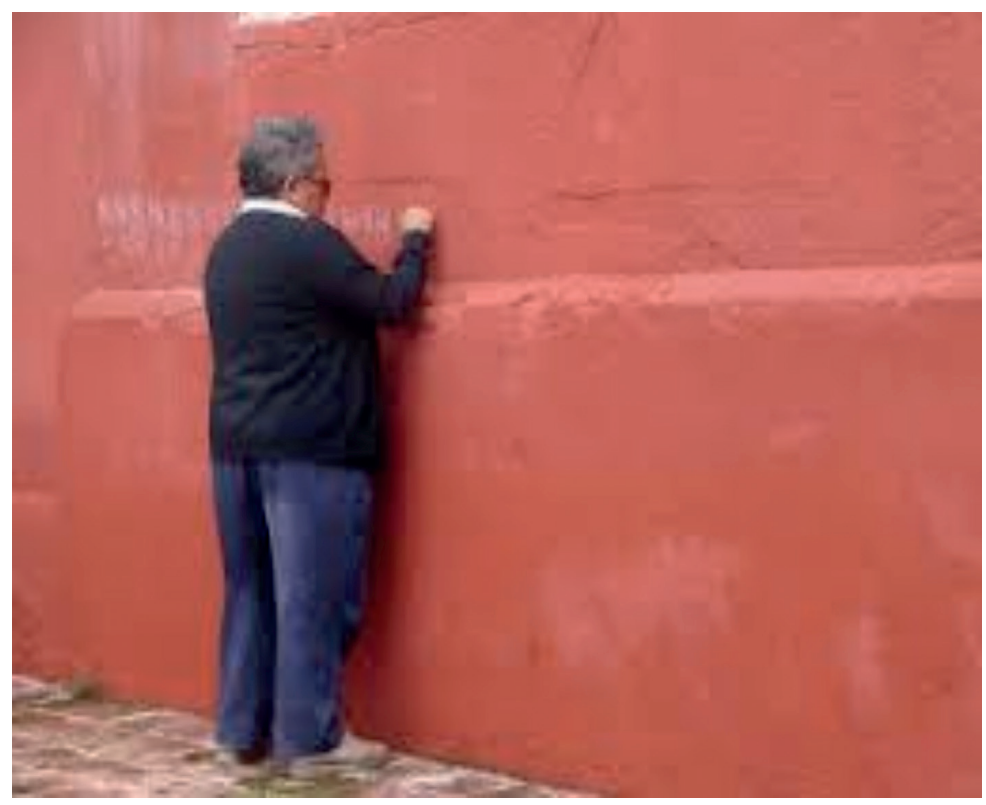

Tomado de: http://losdesaparecidosguatemala.blogspot.com/2008/06/la-actividad-de-performance-inici-este.html

$62 \mathrm{El}$ arte y la literatura en la construcción y disputa de la memoria en Guatemala Rafael Cuevas Molina 
En 2009 conversé con ella en su casa en el Barrio del Cementerio, en la Zona 3, de Ciudad de Guatemala. Me comentó la actitud hostil de muchos transeúntes que, al verla rayar las paredes del ex-Convento de la Compañía de Jesús, la increpaban por estar dañando patrimonio nacional. "Se enojan porque aparentemente daño restos de la memoria colonial guatemalteca" -me dijo entonces- "pero no se dan cuenta que estoy llamando su atención sobre una memoria de hechos más cercanos que no quieren ver".

El otro trabajo de Isabel al que quiero hacer mención es la instalación Rio Negro. La comunidad de Río Negro vivía a las orillas del río Chixoy (también conocido como Río Negro), en el territorio de Baja Verapaz. El valle ha sido habitado por los mayas, desde el año 300 a.n.e. hasta el 900 a.n.e. y fue la sede de muchos enterramientos ceremoniales. La tierra era la fuente del sustento para sus habitantes, a la vez que un vínculo con su pasado y su cultura.

El 13 de febrero de 1982, el Ejército le pidió a los habitantes de Río Negro que llevaran sus tarjetas de identificación a Xococ, un poblado cercano en donde estaba acuartelado, y volvieran una semana después a recoger las nuevas tarjetas. Setenta y cuatro habitantes hicieron el viaje, y 73 no volvieron nunca. Una mujer aterrorizada volvió corriendo a Río Negro y anunció que estaban asesinando a todos. La comunidad decidió que sería más seguro si los hombres que quedaban huyeran a las montañas. Creían de que no harían daño a las mujeres y los niños.

Un mes después, la noche del 13 de marzo, patrullas de autodefensa civil de la vecina Xococ llegaron a Río Negro y mataron a 117 mujeres y niños. Para escapar de los soldados enfurecidos y de las patrullas de autodefensa, 24 personas se escondieron en la selva. Dos meses más tarde, el ejército atacó y mató a otras 84 personas en un lugar llamado Los encuentros, en el mismo valle del Río Negro. Se llevaron a quince mujeres en helicóptero, a las que nunca se les volvió a ver y que recién el año pasado se supo, por el juicio conocido como de la masacre de CREOMPAZ, que fueron trasladadas a un destacamento militar en el departamento de Alta Verapaz y ultimadas. Una fosa común encontrada da cuenta de por lo menos 538 osamentas.

Isabel Ruíz reflexiona sobre estos hechos plásticamente en su serie Río Negro. Su propuesta se propone denunciar y protestar los extremos a los que llegó la represión política en Guatemala. No es este, sin embargo, su único trabajo. Historia sitiada, 30 años de silencio y otras tienen la misma tesitura.

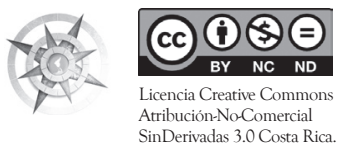


Fotografía 3. Isabel Ruíz. Río Negro. Guatemala, 2008.

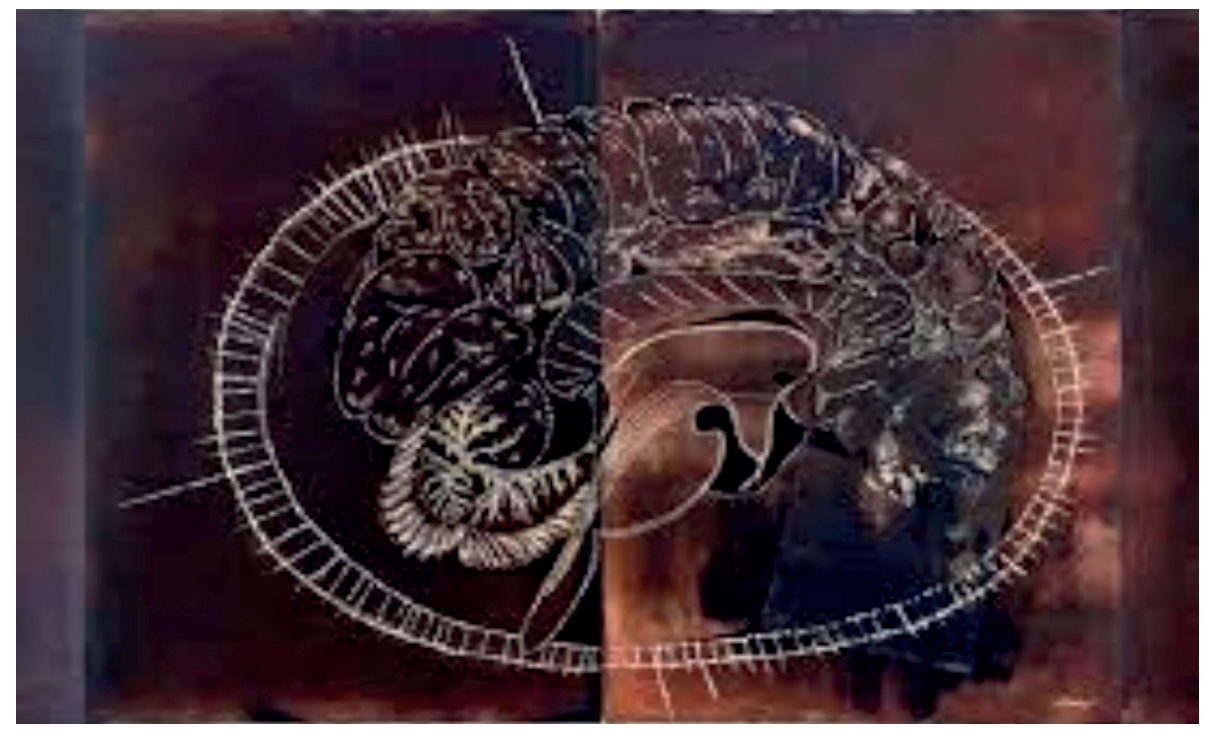

Tomado de: http://www.prensalibre.com/vida/escenario/las-tres-decadas-de-isabel-ruiz

Daniel Hernández es un fotógrafo y restaurador que se autodefine como un fotógrafo artístico y documental. Él trabaja sobre la memoria histórica. Uno de sus principales proyectos fue la exposición de fotografías sobre el expresidente Jacobo Arbenz, derrocado con la complicidad de los Estados Unidos en 1954. Su fotografía Memoria de un Ángel se imprimió en la porta del Proyecto Interdiocesano de Recuperación de la Memoria Histórica (REMHI) en el Informe Guatemala: Nunca Más publicado en 1998 por la Oficina de Derechos Humanos del Arzobispado de Guatemala.
Fotografía 4. Daniel Hernández. Un ángel. Guatemala, 1998

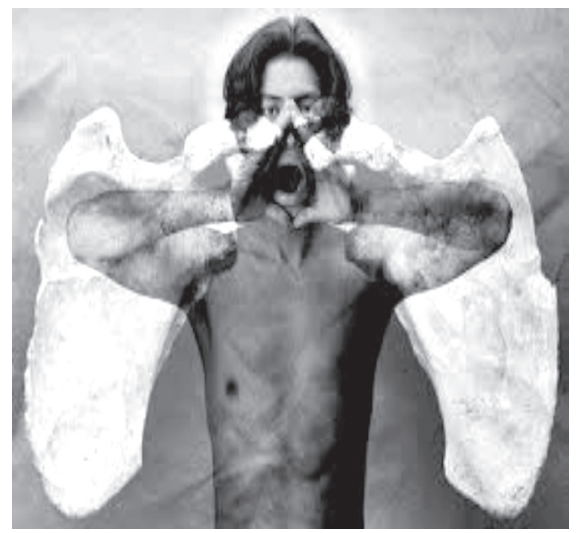

Tomado de: https://www.url.edu.gt/PortalURL/Noticias/noticia_individual. aspx? $\mathrm{n}=170 \& \mathrm{~s}=35 \& \mathrm{c}=3 \& \mathrm{nc}=\operatorname{Arte} \% 20$ y\%20Cultura

$64 \mathrm{El}$ arte y la literatura en la construcción y disputa de la memoria en Guatemala Rafael Cuevas Molina

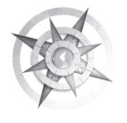


$\mathrm{Su}$ serie Revelación... el poder de la memoria en el país del olvido hace referencia a la información que se muestran en el Diario Militar, que es el nombre que recibe un listado de 183 personas desaparecidas a manos de las fuerzas de seguridad guatemaltecas entre agosto de 1983 y marzo de 1985. Fue publicado por primera vez en mayo de 1999 por la revista Harpers Magazine y está considerado como un documento único en su género, ya que prueba la sistematización de la represión en Guatemala durante las dictaduras militares que ensangrentaron el país.
En ocasión de esta exposición, el artista declaró:

Decidí dedicar mi esfuerzo a la recolección y transmisión de la memoria histórica con documentos visuales. Me he dado cuenta que en Guatemala se usa la negación como mecanismo de protección y defensa pero también como herramienta de dominación; además, en el extranjero hay una gran ignorancia de Guatemala y su holocausto, como quiero llamarle.

Uno puede poner su grano de arena, porque si todos hacemos lo

Fotografía 5. Daniel Hernández. Revelación... el poder de la memoria en el país del olvido. Guatemala, 2012

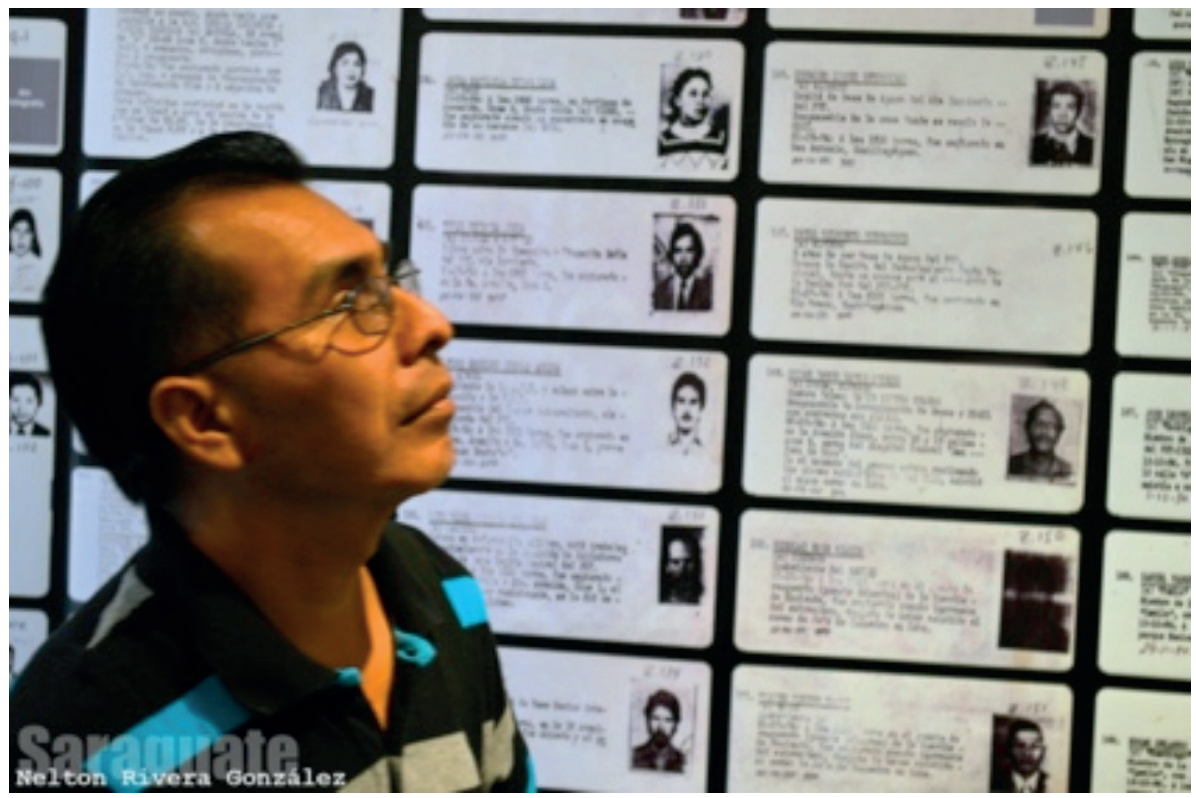

Tomado de: https://comunitariapress.wordpress.com/tag/daniel-hernandez-salazar/

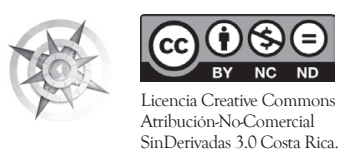


mismo talvez podemos avanzar; considero que el trabajo de los artistas no debe de quedarse solamente en donde a veces se queda, en el arte como algo decorativo, como un objeto que sirve para decorar, sino debe ser una disciplina que lucha, y desde la cual un fotógrafo, o los artista en general, podemos incidir en la sociedad. Verlo como una herramienta y no como un adorno (https://comunitariapress.wordpress.com/ tag/daniel-hernandez-salazar/).

El Museo del Holocausto y Derechos Humanos de Bélgica termina, desde el 2013, todo su recorrido de cinco pisos con la pieza Un Ángel que creó Daniel Hernández para la portada del Proyecto Interdiocesano de Recuperación de la Memoria Histórica, la cual quedó de forma permanente.

El trabajo de Hernández recubre un valor personal especial para mi persona. Mi hermano, Carlos Ernesto aparece en el Diario Militar mencionado. En la entrada que le corresponde, la 132, aparece consignada su captura el 15 de mayo de 1984 y su muerte, codificada bajo el número 300, el 1 de agosto del mismo año.

En 2009, después de un viaje a Guatemala desde Costa Rica con mis hijas, especialmente conmovido después de mostrarles a ellas los sitios en donde habíamos vivido con mi familia, en donde se habían producido acontecimientos trágicos de nuestra vida, entre ellos la esquina en donde habían secuestrado a su tío, escribí la novela 300 , que hace alusión a ese código del Diario Militar.

En dicha novela trabajo sobre memorias que los guatemaltecos tenemos del período de la guerra, especialmente de los años ochentas. La obra se estructura como pequeñas entrevistas que se suceden sin solución de continuidad formando lo que llamo un espejo trizado. Las entrevistas no existieron, fueron producto de mi imaginación documentada, es decir, de la memoria que guardo de todos estos años en los que sufrimos la represión, el exilio y la muerte de seres queridos.

Menciono mi novela porque es un trabajo que se inscribe en una de las corrientes de la literatura guatemalteca de los años noventas hacia el presente. Digo que forma parte de una de las corrientes de ese tipo de literatura porque, a mi entender, hay por lo menos dos relativas a la memoria: la que gira en torno a la guerra y la represión, y la que se preocupa más por mostrar las desavenencias, las falencias, las desviaciones y lo errores de los grupos y los militantes de izquierda durante la guerra. Esta última ha sido denominada como literatura del desencanto o del cinismo (Beatriz

$66 \mathrm{El}$ arte y la literatura en la construcción y disputa de la memoria en Guatemala Rafael Cuevas Molina 
Cortés, 2010) y ha sido escrita por antiguos militantes de grupos insurgentes. Es la que más atención recibe por parte de la crítica. En Guatemala la inaugura Marco Antonio Flores con su novela Los compañeros en época tan temprana como 1976, y hoy tiene entre sus representantes a Arturo Arias y Mario Roberto Morales.

Independientemente de cómo se trate la relación con el pasado, del balance o las conclusiones que se saquen de las actuaciones personales ficcionalizadas que ahí se muestran, la memoria es un eje alrededor del cual gira este tipo de literatura en Guatemala. Es una literatura que tiene varias funciones: la catarsis, por ejemplo, es una. Dejar testimonio es otra, como por ejemplo en Los días de la selva (1981) de Mario Payeras. Es esta una tendencia que tiene una visión epopéica de la guerra insurgente; que se pensó a sí misma como parte de una memoria futura en la que habría que mostrar cómo se había construido la utopía a la que entonces se aspiraba.

Pero también es una literatura que tiene otras funciones en Guatemala como, por ejemplo, el ajuste de cuentas, donde la literatura se usa como instrumento para tratar de reivindicarse personalmente de hechos en los que se entiende que se fue vejado o lastimado y donde la denuncia se orienta no hacia los extremos opuestos del espectro ideológico sino hacia los que, como dice Flores, eran "los compañeros”. La más representativa de este tipo de literatura es la obra de Mario Roberto Morales, Los que se fueron por la libre (1996) o El esplendor de la pirámide (1985)

Pero, independientemente de cómo se aborde la memoria y hacia dónde se enfilen los dardos que su interpretación produzcan, la literatura que la tiene como eje es patrimonio, con pocas excepciones, de quienes fueron militantes de izquierda, o simpatizan hoy con posiciones humanísticas. Prácticamente no encontramos ninguna obra de alguien del campo opuesto que reivindique al Ejército, la represión o el entorno de lo que podríamos llamar el Estado contrainsurgente guatemalteco. Personalmente conozco solamente un pequeño trabajo, una novela corta de apenas 101 páginas, en pequeño formato, sin casa editorial que la respalde, firmada, probablemente con seudónimo, por Gustavo Pinto y que se titula El camino de un lobo. Este es un trabajo en el que aparece con mucha evidencia la necesidad de enaltecer los hechos perpetrados por el Ejército guatemalteco en la década más dura de la guerra, la de los años ochentas, y que llega hasta el delirio de atribuir a los Kaibiles la caída del Muro de Berlín. 
No es este el lugar en donde podamos hacer comparaciones de este tipo de arte y literatura con otras corrientes que, sin que tengan a la memoria como punto central, también tratan sobre ella como un referente de lo que se es, se ha sido, lo que se quiere ser o se rechaza. Sí queremos remarcar, para concluir, el espacio de disputa en el que se ha convertido la memoria en Guatemala, y el papel relevante que en esta tienen el arte y la literatura.

\section{Referencias bibliográficas}

Barrios, Moisés. Página de literatura guatemalteca. Disponible en http://www.literaturaguatemalteca.org/rjgalindo.htm.)

Brailovsky, A. (1997). "El ambiente en la sociedad colonial". Buenos Aires: Ministerio de Cultura y Educación de la Nación.

Cortés, B. (2010). Estética del cinismo - pasión y desencanto en la literatura centroamericana de posguerra. Guatemala: FyG.

Halbwachs, E. (1992): The Legendary Topography of the Gospels in the Holly Land. University of Chicago Press.

Nora, P. (1998) Las aventuras de lieux de mémoire. Ayer, 32, pp. 17-34 